\title{
Vault Haematoma after Vaginal Hysterectomy
}

\author{
Batish $A^{1}$, Sathiyathasan $S^{1}$, Jeyanthan $K^{2}$ \\ ${ }^{1}$ Kings College Hospital NHS Trust, London, ${ }^{2}$ Croydon University Hospital, London
}

Received: May 8, 2013; Accepted: November 19, 2014

\begin{abstract}
Electronic searches of literature published between 1980 and 2014 were undertaken using MEDLINE, Embase, CINHAL, and the Cochrane Database of Systemic reviews. Search items included: haematoma, hysterectomy, morbidity, ultrasound. The incidence of vault hematomas varied from $25-59 \%$ in various studies. Small hematomas can be managed conservatively and large and infected hematomas need incision and drainage. However various studies found no correlation between the presence of a collection and indices of postoperative morbidity. Also routine scan was not indicated. The incidence of vault hematomas is due to inadequate haemostasis and refining the surgical technique significantly reduces the risk of vault hematomas.
\end{abstract}

Keywords: haemostasis; vaginal hysterectomy; vault haematoma.

\section{INTRODUCTION}

"Every hysterectomy should be considered as vaginal unless there is a contraindication". ${ }^{1}$ The most common operation performed in gynaecology is hysterectomy. Vault hematoma is the most common complication of vaginal hysterectomy. Vaginal route of hysterectomy is preferred than the abdominal as it has its own advantages like shorter duration of surgery, shorter hospital stay, and early ambulation. Thus the clinicians today are more likely to be exposed to the complication of vault haematoma and can face problem while managing it. Here we reviewed the incidence of vault hematomas, dealt with the management and looked into the ways to reduce the incidence.

\section{METHODS}

Electronic searches of literature published between 1980 and 2014 were undertaken using MEDLINE, Embase, CINHAL, and the Cochrane Database of Systemic reviews. Search items included: haematoma, hysterectomy, morbidity, ultrasound methods.

\section{CORRESPONDENCE}

Dr Avni Batish

Princess Royal University Hospital, Kings College Hospital NHS Trust, Kent, BR6 8ND, UK.

Email: a.batish@nhs.net

Phone: +01689863000

\section{RESULTS}

A systematic review of randomised trials concluded that, where possible, vaginal hysterectomy should be performed in preference to abdominal hysterectomy for benign gynaecological disease. ${ }^{2}$ The incidence of vaginal hysterectomy is rising as it is increasingly being done for non prolapsed uterus also. Currently vaginal hysterectomy is becoming more popular as it has its own advantages like; shorter duration of surgery, shorter hospital stay, and early ambulation. As a result of the increase in the use of vaginal hysterectomy it is therefore important to ensure that common complications are either eliminated or minimised. Vault haematoma is the most common complication of vaginal hysterectomy. Even though vaginal hysterectomy has lower risks compared with abdominal hysterectomy, it is associated with a significant risk of vault haematomas ranging from $25 \%-59 \%{ }^{3-5}$ The incidence of vault hematoma after vaginal hysterectomy is variably reported - from approximately $25 \%$ to as high as $98 \%{ }^{5-7}$ Such disparity in diagnosis may be due to differing definitions of vault hematoma and/or diagnostic modalities. Fluid collection at the vault after hysterectomy could be blood, lymph, or serous fluid with necrotic debris. It is collected in the dependent areas. Hematomas are usually seen in the pouch of Douglas, subvesical space, ischiorectal fossa, and broad ligament. ${ }^{8}$ Postoperative hematoma can cause serious morbidity if it is large and infected. A haematoma represents the most common perioperative complication following 
vaginal hysterectomy and is significantly associated with febrile morbidity, postoperative haemoglobin drop, anaemia, pelvic discomfort, secondary haemorrhage, blood transfusion and need for further hospital admission and operations such as evacuation of haematoma. ${ }^{9}$

Many patients may be asymptomatic; whereas some may present with postoperative bleeding per vaginum (spotting to profuse bleeding per vaginum) postoperative discomfort, abdominal distension, paralytic ileus, continuous fever, foul smelling discharge per vaginum, abscess formation, tenesmus, nausea, vomiting, and diarrhoea. Some authors suggested that the presence of sonographically diagnosed pelvic hematoma is associated with febrile morbidity ${ }^{3}$ while others were unable to demonstrate such a relationship. ${ }^{5,10,11}$ Postoperative pelvic hematoma can cause serious morbidity, especially if it is large and becomes infected. Postoperative febrile morbidity was sixteen times more common in subjects with hematoma compared to those without hematoma. Toglia and Pearlman supported this finding as $69 \%$ of women with postoperative pelvic collection experienced febrile morbidity compared to $12 \%$ of those with no collection in their study. ${ }^{12} \mathrm{~A}$ study by Thomson et $\mathrm{al}^{3}$ demonstrated the incidence of febrile morbidity to be $31 \%$ in patients with vaginal vault hematomas. However, studies of small sample populations have concluded that collections of fluid at the vaginal vault following hysterectomy do not contribute to postoperative morbidity. Although Haines and Slavotinek found no significant relation between the detection of vault hematoma and their defined parameters for postoperative morbidity, each study did show a trend towards an increase in febrile morbidity in patients with a hematoma..$^{5,11}$

\section{How to prevent formation of haematomas and reduce morbidity}

Haematomas form as a result of inadequate haemostasis during the operation. Wood et $\mathrm{al}^{4}$ suggested that greater attention to haemostasis is required at vaginal hysterectomy as the limited access available during the procedure may contribute to higher rates of postoperative bleeding. The use of prophylactic antibiotics has been clearly shown to have a significant role in the reduction of infection, and is now standard practice in the United Kingdom. ${ }^{13}$

\section{Refining the surgical technique}

Morris et $\mathrm{al}^{9}$ found that following refinement in surgical technique a significant reduction in the incidence of clinically significant vaginal vault haematomas from $15.7 \%$ to $1.7 \%(\mathrm{P}<0.001)$ was observed over a 4 -year period. The authors described the following: The initial incision around the anterior portion of the cervix is performed in a circumferential manner between the transverse cervical ligaments (9 and3 o'clock). Posteriorly the incision is made from the lateral angle of the anterior incision in a posteromedial direction on each side, resulting in a 'V'shape. Closure of the vault is commenced posteriorly in a vertical direction with an absorbable suture material in a locking fashion. During suturing it will be seen that the peritoneum remains attached to the vaginal skin, and that bleeding from this area is minimal. In starting posteriorly the peritoneum is included in the suturing until the uterosacral ligaments are reached. At this point it is no longer possible to incorporate the peritoneum into the suture line, as it has been incorporated into the pedicles of the uterosacral ligament and then over the bladder. After the uterosacral ligaments have been included in the running suture to approximate them together in the midline, closure is then completed using the vaginal skin alone. Therefore, above the level of the uterosacral ligaments, the peritoneum is not closed and the vascular pedicles are not tied together nor brought to the midline. More recently, the use of a bipolar vessel sealing system (Ligasure, Autosuture, Valleylab, Boulder, CO, USA) during vaginal hysterectomy was shown to reduce the incidence of perioperative haemorrhagic complications. ${ }^{14}$ The first randomised controlled trial to assess the effect of routine vault drainage during vaginal hysterectomy on morbidity suggests that the routine use of vault drainage does not influence immediate postoperative morbidity hence it is not recommended. ${ }^{15}$

\section{Management of hematomas}

Small vaginal vault hematomas $(2-3.9 \mathrm{~cm})$ are unlikely to cause postoperative morbidity and can be managed expectantly. They can be left alone with watchful expectancy and follow-up ultrasonography for resolution of the hematoma done weekly. ${ }^{16}$

Moderate $(4-5.9 \mathrm{~cm})$ and large $(>6 \mathrm{~cm})$ vaginal vault hematomas need further management. An extended 
morbid and complicated postoperative course can be alleviated if the hematoma can be drained. A small penrose drain may be inserted through the drainage tract and left in place for a day or so. If drainage cannot be achieved in this simple way, drainage with guidance of ultrasonography, or if it fails, then using computed tomography or through an abdominal incision may be necessary. If the hematoma can be drained the patient's recovery will be more prompt. In exceptional cases where drainage may be difficult or contraindicated and infection is not a serious problem, the hematoma may be allowed to gradually resolve over a few months. ${ }^{17}$

\section{CONCLUSIONS}

The incidence of vault hematomas is more following vaginal hysterectomies due to inadequate haemostasis and infection. No routine scan is indicated. Small haematomas can be managed conservatively however large infected hematomas need culture and sensitivity of pus and drainage under anaesthesia. Refining the surgical technique will significantly reduce the risk of vault hematomas.

\section{DISCLOSURE}

The authors report no conflicts of interest in this work.

No violation of human rights and safety.

Funding: Nil

\section{REFERENCES}

1. Qinlan DK. Indication and contraindication: vagina hysterectomy. In: Sheth SS, Studd J, editors. Vaginal hysterectomy. 1st edn. London: Martin Dunitz Ltd; 2002.

2. Nieboer TE, Johnson N, Lethaby A, Tavender E, Curr E, Garry R, et al. Surgical approach to hysterectomy for benign gynaecological disease. Cochrane Database of Systematic Reviews 2009; 3:CD003677.

3. Thomson AJM, Sproston AR, Farquharson RG. Ultrasound detection of vault haematoma following vaginal hysterectomy. BJOG. 1998;105:211-5.

4. Wood C, Maher P, Hill D. Bleeding associated with vaginal hysterectomy. ANZJOG. 1997;37:457-61.

5. Slavotinek J, Berman L, Burch D, Keefe B. The incidence and significance of acute post-hysterectomy pelvic fluid collections. Clinical Radiology. 1995;50:322-6.

6. Kuhn RJP, de Crespigny LC. Vault haematoma after vaginal hysterectomy: an invariable sequel? ANZJOG. 1985;25(1):59-62.

7. Rosen DMB, Cario GM. Vault haematoma following laparoscopic hysterectomy. ANZJOG. 1997;37(2):220-2.

8. Kulkarni S, Vijaya N. Detection of vault hematoma by ultrasound scan following hysterectomy and its correlation with morbidity. JOGI. 2006;56(6):507-10.

9. Morris EP, El-Toukhy T, Toozs-Hobson P, Hefni MA. Refining surgical technique to prevent recurrence of vault haematoma after vaginal hysterectomy. J Obstet Gynaecol. 2001;21(4):379-82.
10. Eason E, Aldis A, Seymour RJ. Pelvic fluid collection by sonography and febrile morbidity after abdominal hysterectomy. Obstet and Gynecol. 1997;90(1):58-62.

11. Haines CJ, Shan YO, Hung TW, Chung TKH, Leung DHY. Sonographic assessment of the vaginal vault following hysterectomy. Acta Obstet Gynecol Scand. 1995;74(3):220-3.

12. Toglia MR, Pearlman MD. Pelvic fluid collections following hysterectomy and their relation to febrile morbidity. Obstet Gynecol. 1994;83:766-70.

13. Dicker RC, Greenspan JR, Strauss LT, Cowart MR, Scally MJ, Peterson HB, et al. Complications of abdominal and vaginal hysterectomy among women of reproductive age in the United States. AJOG. 1982;144:841-8.

14. Hefni MA, Bhaumik J, El-Toukhy T, Kho P, Wong I, Abdel-Razik T, et al. Safety and efficacy of using the Ligasure vessel sealing system for securing the pedicles in vaginal hysterectomy: randomised controlled trial. BJOG. 2005;112:329-33

15. Dua A, Galimberti A, Subramaniam M, Popli G, Radley S. The effects of vault drainage on postoperative morbidity after vaginal hysterectomy for benign gynaecological disease: a randomised controlled trial. BJOG. 2012;119:348-53.

16. Dane C, Dane B, Cetin A, Yayla M. Sonographically diagnosed vault hematomas following vaginal hysterectomy and its correlation with postoperative morbidity. Infect Dis Obstet Gynecol. 2009;2:91708.

17. Rock JA, Thompson JD, editors. Te Lende's operative gynaecology. 8th edn. Philadephia: Lippincott-Raven; 1996. 